\title{
Characterization of the Mesorhizobium loti MAFF303099 Type-Three Protein Secretion System
}

\author{
Cintia Sánchez, ${ }^{1}$ Florencia lannino, ${ }^{1}$ William J. Deakin, ${ }^{2}$ Rodolfo A. Ugalde, ${ }^{1}$ and Viviana C. Lepek ${ }^{1}$ \\ ${ }^{1}$ Instituto de Investigaciones Biotecnológicas, INTECH, Universidad Nacional de General San Martín, CONICET, \\ Buenos Aires, Argentina; 'Laboratoire de Biologie Moléculaire des Plantes Supérieures (LBMPS), Sciences III, \\ 30 Quai Ernest-Ansermet, Université de Genève, $\mathrm{CH}-1211$ Geneva 4, Switzerland
}

Submitted 9 December 2008. Accepted 20 January 2009.

\begin{abstract}
Type III secretion systems (T3SS) have been found in several species of rhizobia. Proteins (termed effectors) secreted by this system are involved in host-range determination and influence nodulation efficiency. Mesorhizobium loti MAFF303099 possesses a functional T3SS in its symbiotic island whose expression is induced by flavonoids. As in other rhizobia, conserved cis-elements (tts box) were found in the promoter regions of genes or operons encoding T3SS components. Using a bioinformatics approach, we searched for other $t$ ts-box-controlled genes, and confirmed this transcriptional regulation for some of them using lac Z fusions to the predicted promoter regions. Translational fusions to a reporter peptide were created to demonstrate T3SS-mediated secretion of two new MAFF303099 effectors. Finally, we showed that mutation of the $M$. loti MAFF303099 T3SS affects its competitiveness on Lotus glaber and investigated, at the molecular level, responses of the model legume $L$. japonicus to the T3SS.
\end{abstract}

Nodule formation and nitrogen fixation in legume roots is the result of a symbiotic process characterized by a complex and continuous exchange of signals between the plant and rhizobia. Plant flavonoids induce the production of bacterial Nod factors which are responsible for the first morphological and physiological events that trigger the development of nodules. Rhizobia grow and divide inside structures called infection threads formed by an invagination of the plant cell wall and membrane at the tip of curled root hairs. Infection threads filled with bacteria extend through the root hair, then traverse the layers of root cortical cells before finally being released by an endocytic-like process into the nodule cells, where rhizobia differentiate into a nitrogen-fixing state called the bacteroid (Gage 2004).

During nodulation, rhizobia must adapt to many different environmental conditions, including a potential plant defense response that can be induced during the process (D'Antuono et al. 2008; Kouchi et al. 2004; Lohar et al. 2006; Niehaus et al. 1993; Soto et al. 2006; Vasse et al. 1993). Rhizobia have a battery of strategies to colonize, invade, and establish a chronic infection in the plant host (Batut et al. 2004; Gage 2004; Soto et al. 2006). Bacterial polysaccharides were described as important for the suppression of plant defense responses

Corresponding author: V. C. Lepek; Telephone: 54-11-4580-7255; Fax: 54-11-4752-9639; E-mail: vlepek@iib.unsam.edu.ar

* The $e$-Xtra logo stands for "electronic extra" and indicates that a supplemental table is published online.
(D'Haeze et al. 2004; Tellstrom et al. 2007). Antioxidant enzymatic activity (Harrison et al. 2005; Jamet et al. 2003) and inhibitors of ethylene synthesis (Ma et al. 2003) are also used by rhizobia to overcome or suppress plant defense reactions.

Type III secretion systems (T3SS) are present in several species of rhizobia, although originally considered characteristic of plant and animal pathogens. Proteins translocated into host cells by T3SS are called effectors, and several of them affect the regulation of host defense signaling (Alfano and Collmer 2004; Bartsev et al. 2004; Chisholm et al. 2006; Desveaux et al. 2007; Skorpil et al. 2005). In Bradyrhizobium japonicum USDA110 (hereafter USDA110), Rhizobium sp. strain NGR234 (hereafter NGR234), and Sinorhizobium fredii strains, T3SS and effectors secreted by them can be involved in nodulation efficiency or host range determination (de Lyra et al. 2006; Krause et al. 2002; Lorio et al. 2004; Viprey et al. 1998). T3SS null mutants can negatively affect nodule formation on usual legume hosts but can also form active nodules on legume species not normally nodulated by the wild-type rhizobia. It was suggested that, as for pathogenic bacteria (Büttner and Bonas 2002; Dangl and Jones 2001), effectors translocated by rhizobial T3SS may suppress or subvert the defense response in some legumes or induce a strong defense reaction that interferes with nodulation in others (Lorio et al. 2004; Skorpil et al. 2005; Soto et al. 2006).

Like Nod factors, expression of rhizobial T3SS components and effectors are induced by flavonoids. Induction of TtsI, the transcriptional activator of rhizobial T3SS, also requires NodD, because it contains a nod box (NB) consensus sequence in its promoter region (Krause et al. 2002; Marie et al. 2004). TtsI then binds to $t t s$ boxes (TB) found in the promoters of genes involved with the T3SS to activate their transcription (Wassem et al 2008). Searching in silico for the TB consensus sequence in the genomes of rhizobia can predict the TtsI regulon and, thus, identify potential effectors secreted by T3SS. TtsI also induces other genes involved in, for example, polysaccharide synthesis, and, thus, does not just control T3SSrelated functions (Marie et al. 2004; Süss et al. 2006).

Within the symbiotic island of Mesorhizobium loti R7A (hereafter R7A) are genes encoding a type IV secretion system (T4SS) as well as two genes (msi059 and msi061) encoding effector proteins (Hubber et al. 2004; Sullivan et al. 2002). Mutation of the T4SS or these effectors permits the formation of functional nodules on Leucaena leucocephala in contrast to R7A itself; conversely, these mutants have reduced competitiveness on Lotus corniculatus (Hubber et al. 2004). Sequencing the M. loti MAFF303099 (hereafter MAFF303099) genome showed that it does not possess a corresponding T4SS but, instead, revealed the presence of all the genes required to 
encode a T3SS (Kaneko et al. 2000a,b). Regulation of the MAFF303099 T3SS could be the same as in other rhizobia because its $t t s I$ homolog is preceded by an NB. Within the cluster of T3SS genes of MAFF303099 there are also conserved TB motifs, upstream of the orthologs of nopC ( $\mathrm{mlr} 8768)$, nopX (mll6337), and nopB (mlr8763) (Krause et al. 2002).

Earlier studies showed that mutation of the MAFF303099 T3SS (just as for the R7A T4SS mutants) allowed the formation of functional nodules by Leucaena leucocephala (Hubber et al. 2004). MAFF303099 also has a gene homologous to the R7A effector-encoding open reading frame (ORF) msi059 (mlr6316). An mlr6316 mutant, however, induces the formation of fewer nodules relative to the T3SS mutant and, thus, it was proposed that MAFF303099 must possess other effectors (Hubber et al. 2004). As well as the M. loti effectors described above, six other candidate effectors have been identified in rhizobia; NopD NopJ, NopL, NopM, NopP, and NopT (Bartsev et al. 2004; Dai et al. 2008; Kambara et al. 2009; Rodrigues et al. 2007; Skorpil et al. 2005). Genes potentially encoding these proteins are not present in MAFF303099, except that Mlr6316 has 50\% similarity to some of NopD (Rodrigues et al. 2007). To search for the other MAFF303099 effectors, we first verified the flavonoid/NodD1/TtsI/TB induction mechanism and functionality of its T3SS, then searched in silico for TB within the MAFF303099 genome. Candidates were identified and further characterized. We also showed that the MAFF303099 T3SS
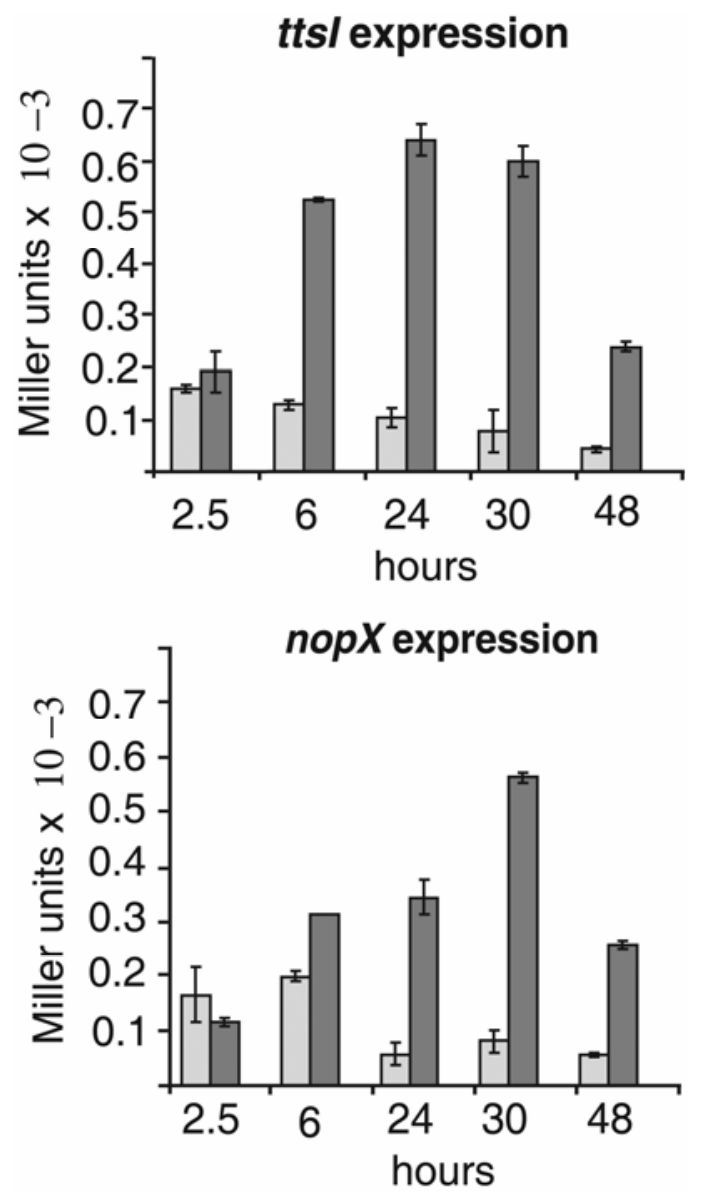

Fig. 1. Expression of $n o p X$ and $t t s I$ promoters fused to lacZ. At the timepoints shown, $\beta$-galactosidase activity was measured. Values are indicated in Miller units, calculated as absorbance (Abs) $420 \mathrm{~nm} \times 1,000 / \mathrm{Abs} 600$ $\mathrm{nm} \times v \times t$, where $v$ is the volume in milliliters and $t$ the reaction time in minutes. Light-gray bars represent noninduced cultures and dark-gray bars show cultures induced by naringenin. The results are averages of three experiments. affects nodulation of Lotus glaber and then, by extension, to the model legume L. japonicus, which permitted a preliminary investigation into the molecular responses of legumes to rhizobial T3SS.

\section{RESULTS}

Nodulation phenotype of $M$. loti T3SS mutants.

Mutation of the MAFF303099 T3SS is necessary to permit efficient nodulation of Leucaena leucocephala (Hubber et al. 2004) but whether it affects nodulation of Lotus spp. was not known. The MAFF303099 gene mlr6342 codes for a protein $87 \%$ similar to RhcN of NGR234, a T3SS protein that shares characteristics of ATPase and whose mutation abolished T3SS secretion (Viprey et al. 1998). The mlr6342 gene was interrupted with a nonpolar gentamycin cassette to create an $r h c N$ mutant of MAFF303099. On L. leucocephala, the same phenotype, as described by Hubber and associates (2004), was observed with the rhcN mutant (i.e., small white nodules with MAFF303099 and large pink nodules with the $r h c N$ mutant) (data not shown).

Nodulation tests were also performed on Lotus glaber seedlings, coinoculating a mixture $(1: 1)$ of the $r h c N$ mutant and wild-type (wt) strains. At 28 days postinoculation (dpi), $68.5 \pm$ $1.5 \%$ of the nodules were occupied only by wt and $27.5 \pm 2.5 \%$ only with the $r h c N$ mutant, indicating that mutation of the T3SS leads to a reduction in the competitiveness of this strain.

\section{Regulation of MAFF303099 T3SS expression.}

To investigate whether the MAFF303099 T3SS is under flavonoid control, the promoter regions of ttsI and nopX were fused to $l a c Z$ and these constructions introduced into MAFF303099 already containing pMP2112, which constitutively expresses nodD of Rhizobium leguminosarum (LopezLara et al. 1995). Because the flavonoid that specifically induces the expression of $M$. loti promoters containing NB is unknown, we used this heterologous system (as proposed by López-Lara et al. [1995]) to induce flavonoid-controlled genes in MAFF303099 with naringenin. Figure 1 shows the expression level of the promoter regions corresponding to ttsI (Fig. 1A) and nopX (Fig. 1B) genes at different post-induction times. Naringenin-dependent expression was observed with both fusions from $6 \mathrm{~h}$ postinduction, and a slight time delay of nopX expression compared with that of $t t s I$ was also observed.

\section{Identification of T3SS-dependent secreted proteins.}

In rhizobia, an established procedure to identify proteins secreted by T3SS is to compare proteins present in culture supernatants of wt and T3SS mutant strains after flavonoid induction (de Lyra et al. 2006; Lorio et al. 2004; Marie et al. 2003; Süss et al. 2006; Viprey et al. 1998). The heterologous NodD induction system brought about expression of T3SS genes; therefore, we used the same strategy to identify secreted proteins in vitro. Proteins were extracted from culture supernatants of MAFF303099 and the $r h c N$ mutant, grown in the presence or absence of naringenin (see Materials and Methods). Proteins were separated by $15 \%$ sodium dodecyl sulfate polyacrylamide gel electrophresis (SDS-PAGE) and stained with silver nitrate. A protein of high mobility (approximate size, $7 \mathrm{kDa}$ ) was seen in supernatant extracts of induced wt cultures but not in noninduced cultures or from induced cultures of the $r h c N$ mutant (Fig. 2A, left panel). The small size and high abundance of this protein indicate that it might be the MAFF303099 homolog of NopA (Marie et al. 2003). The MAFF303099 ortholog (encoded by $m s r 8767$ ) of this protein is $65 \%$ similar to NopA of NGR234. Thus, antibodies against NGR234 NopA were used on Western blots of the same extracted supernatant proteins, which recognized this highly abundant and mobile peptide pre- 
sent only in induced wt samples (Fig. 2A, right panel). Thus, the MAFF303099 T3SS is functional and most likely secretes NopA in the presence of flavonoids.

Intracellular proteins from the same cultures were also examined. Coomassie staining of total protein content revealed no differences between noninducing or inducing or the wt/rhcN mutant extracts (Fig 2B, left panel). Use of the NGR234 antiNopA antibody on these same proteins revealed that NopA accumulated intracellularly in both the wt and $r h c N$ mutant, if grown with naringenin (Fig. 2B, right panel).
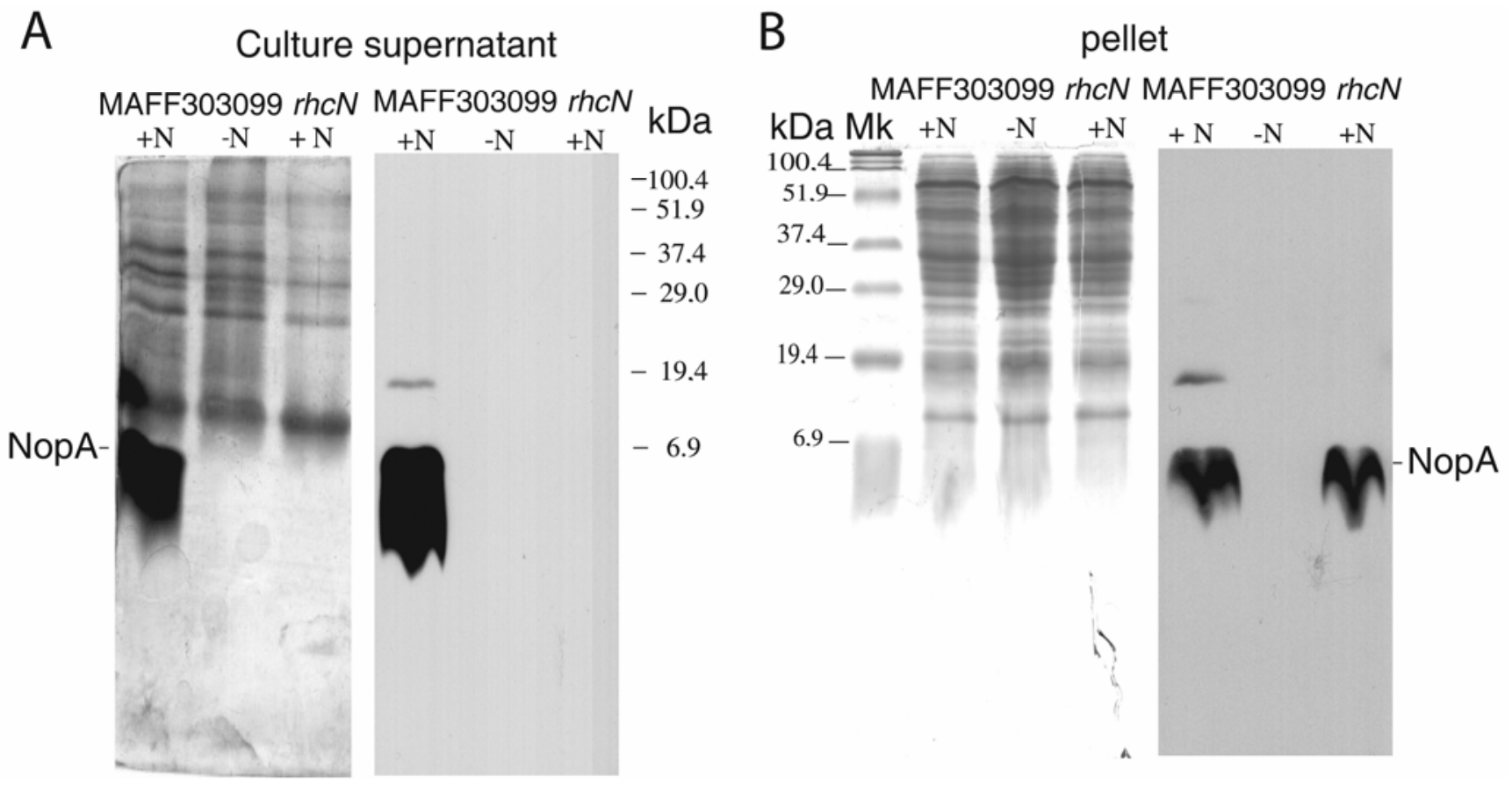

Fig. 2. Analysis of MAFF303099 type III secretion system-secreted proteins. A, Supernatant and B, intracellular proteins were isolated from MAFF303099 and its $r h c N$ mutant grown with or without naringenin. Proteins were separated by $15 \%$ sodium dodecyl sulfate polyacrylamide gel electrophoresis, stained with silver nitrate/Coomassie Blue (left panels), or transferred to membranes and probed with anti-NopA antibody (right panels). The presence or absence of naringenin in cultures is shown by $+\mathrm{N}$ or $-\mathrm{N}$, respectively. The positions of size markers loaded onto the gels are indicated in kilodaltons.

Table 1. Potential tts-box (TB)-controlled genes in the MAFF303099 genome ${ }^{\mathrm{a}}$

\begin{tabular}{|c|c|c|}
\hline Gene ID & Encoded protein & TB sequence \\
\hline mll6337 & NopX & tcGTCAGtttaccGaaAGctaaaccgctca \\
\hline$m l r 8763$ & NopB & caGTCAGcttgtcGtcAGctcggecaccta \\
\hline$m l r 8768$ & NopC & tcGTCAGgttctcGaaAGctcetgctcgta \\
\hline$m l r 6361$ & Shikimato kinase-like & ccGTCAGctaatcGtcAGccaagcgatcta \\
\hline mlr6358 & Unknown protein & gcGTCAGctcaccGtcAGctcgttcgagta \\
\hline mlr6331 & Shikimato kinase-like & agGTCAGagtcacGtcAGgtgaaggggata \\
\hline mlr6316 & Homologue of msi059 of $M$. loti R7A & ccGTCAGcttgtcGtaAGccaaccegccta \\
\hline mlr4967 & Sugar (D-Ribose) ABC transporter & tcGTCAGtctgccGgaAGgccggcecgcta \\
\hline mll8374 & Hypothetical protein & atGTCAGtgcctcGaaAGcggtgcceggca \\
\hline mlr4593 & Transcriptional regulator & gcGTCAGctccgcGgaAGcgecgtcgctga \\
\hline$m l r 5253$ & Exopolysaccharide production repressor (ExoX) & ctGTCAGagtggcGacAGgttgaaaggccg \\
\hline$m l r 7346$ & Transcriptional regulator (LysR type) & ccGTCAGgttttGegAGcggcgtcgatcg \\
\hline$m l r 4647$ & Cytochrome b561 & ttGTCAGcgaactGacAGcttggcegttcc \\
\hline mll7088 & Similar to LpsC & gaGTCAGttgcgcGacAGggacaaccecgc \\
\hline mlr6398 & Conjugal transfer protein, $\mathrm{TrbC}$ & aaGTCAGgggegcGgaAGcgetggacatgc \\
\hline mll2260 & Probable tetracycline repressor protein & caGTCAGtcgcctGgaAGgagggatggatg \\
\hline$m l r 7106$ & Probable dehydrogenase & gaGTCAGgtcattGacAGgcgcactggtgc \\
\hline$m l r 8432$ & Transcriptional regulator & gtGTCAGgttcacGatAGcgtgacggtgtg \\
\hline mll7788 & Hypothetical protein & ggGTCAGcgcggaGgaAGcctgatggeggc \\
\hline mll9677 & Hypothetical protein & ggGTCAGtcgcaaGaaAGggaatgacgacg \\
\hline mll6735 & Arginine/ornithine antiporter & ccGTCAGtgcggcGagAGaaagcttctgcg \\
\hline mll9677 & Hypothetical protein & agGTCAGgcgettGaaAGaaccattcceag \\
\hline mll4959 & Unknown protein & caGTCAGcacctgGtcAGgcggcgtcgcgg \\
\hline$m s r 8615$ & Unknown protein & cgGTCAGccagctGgaAGaaacgctcgaca \\
\hline mlr5805 & Cytochrome $\mathrm{c}$ peroxidase & atGTCAGgtccgcGtcAGaatcgattttaa \\
\hline mll3242 & Cyclase & gcGTCAGccatgtGcgAGgtgcgactgggc \\
\hline mll4958 & Hypothetical protein & ccGTCAGattcggGtgAGagcgctatggat \\
\hline
\end{tabular}

${ }^{a}$ Code numbers of the genes downstream of the identified TBs are listed, as well as the names of the (first) encoded protein (if known). The TB consensus sequence determined by Krause and associates (2002, which was slightly modified by Marie and associates (2004), comprises 30 nucleotides and consists of the sequence tcGTCAGctt . tcGaaAGct.. gcc . c. ta, where capital letters indicate the invariant nucleotides and lowercase letters were used for nucleotides present in the majority of the sequences. We used only the invariant nucleotides in our searches but then indicated potential TB sequences with all 30 nucleotides. 
Analysis of lower mobility proteins on $10 \%$ SDS-PAGE revealed other proteins secreted by MAFF303099 but not by its $r h c N$ mutant (data not shown). Mass spectrometry analysis revealed that one of them (of approximately $80 \mathrm{kDa}$ ) contains the peptide AAIEGLQQDPELFYAIGSQGDGR which allowed its identification as an ortholog of NopX, a known T3SSsecreted protein of rhizobia.

\section{Identification of other genes potentially controlled by TB.}

Analysis of the MAFF303099 genome in silico revealed the presence of promoter regions containing sequences significantly homologous to the TB consensus (Krause et al. 2002; Marie et al. 2004). Interestingly, besides the presence of TB upstream of nopX (mll6337), nopC (mlr8768), and nopB ( $m l r 8763)$ as described in other rhizobia (Krause et al. 2002; Marie et al. 2004), a series of other genes contain TB in their promoter region (Table 1). The proteins encoded by these genes are potentially substrates for secretion by the MAFF303099 T3SS. Four of these ORF, including mlr6316, the ortholog of R7A msi059, as well as mlr6331, mlr6358, and $m l r 6361$, are located in the symbiotic island, flanking the MAFF303099 T3SS cluster (Fig. 3). However, the majority of the genes listed in Table 1 are located in chromosomal regions outside of the symbiotic island.

Transcriptional lac $Z$ fusions were made to the TB-containing upstream regions of $\mathrm{mlr6331}$, mlr6358, mlr6316, and $\mathrm{mlr6361.}$ The regulation of other interesting candidates was also checked by fusing their promoter regions to lacZ. The ORF mlr4967 potentially encodes an ABC transporter, $m l r 5253$ encodes a homolog of ExoX (a repressor of exopolysaccharide production), and $m l r 7346$ a LysR-type transcriptional regulator (Table 1). Induction of lac $Z$ expression in the presence of $R$. leguminosarum NodD and naringenin after $30 \mathrm{~h}$ was observed only with $m l r 6316$, mlr6331, mlr6358, and mlr6361 (Fig. 4). The promoters of $m l r 4967, m l r 5253$, and $m l r 7346$ were all active but did not respond to naringenin (Fig. 4).

\section{Description of candidate \\ MAFF303099 effector-encoding genes.}

Based upon earlier studies (Hubber et al. 2004), mlr6316 is suspected of encoding an MAFF303099 effector. The three other TB-controlled ORF, adjacent to the T3SS locus, also potentially encode effectors. An in silico analysis of the proteins potentially encoded by them was performed. mlr6361 codes for a predicted protein of 3,056 amino acids (aa) containing, at the carboxyl (C)-terminal, a domain of approximately 200 aa, 59\% similar to shikimate kinase enzymes. The region between amino acids 881 and 2,892 displays 47 to $49 \%$ similarity to putative effectors of Pseudomonas syringae, Ralstonia solanacearum, and Xanthomonas axonopotis. This region contains a conserved multidomain sequence (PRK09169; Conserved Domain Database) present in numerous hypothetical proteins. mlr6331 encodes a putative protein of 2,373 aa, $68 \%$ similar to the C-terminal 2,360 aa of the translated product of mlr6361. Finally, mlr6358 ORF codes for a predicted protein of 812 aa, $54 \%$ similar to the N-terminal 684 aa residues of the predicted protein codes by ORF $m l r 6361$. This region also presents 58 and $68 \%$ similarity to B. japonicum blr1704 and blr1854, respectively, which also have TB in their promoter regions. Recently, it was described that blr1704 expression was induced by Glycine max exudates (Wei et al. 2008).

In phytopathogenic bacteria, proteins secreted by T3SS have a characteristic amino $(\mathrm{N})$-terminal amino acid composition. Effectors secreted by the T3SS of $P$. syringae have at least two of the following features: (i) at least $10 \%$ Ser residues within the first 50 aa residues; ii) Ile, Val, or Pro located in the third or fourth amino acid residue; and iii) no Asp or Glu residues within the first 12 aa residues (Schechter et al. 2004). The presence, or not, of these characteristic features in the MAFF303099 Nop homologs and the putative effectors are shown in Table 2. Only the Nops and the product of the mlr6361 gene were found to have at least two of these features. Although mlr6358 does not have a conserved secretion amino acid pattern in the ORF annotated in Rhizobase (the genome database for rhizobia), it should be noted that there is another possible (in-phase) start site 63 nucleotides downstream. Translation of this alternative ORF generates a protein with an $\mathrm{N}$ terminal region containing the proposed secretory characteristics (Table 2).

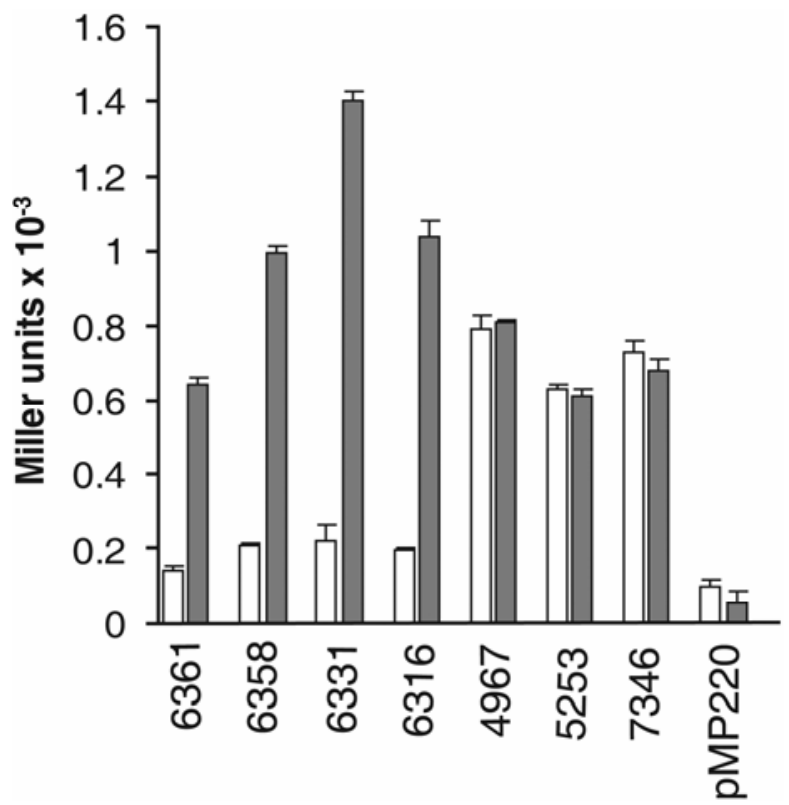

Fig. 4. Expression of selected tts box-containing promoters fused to lacZ. $\beta$-Galactosidase activity was measured after growth for $30 \mathrm{~h}$. White bars represent noninduced cultures and gray bars show cultures induced by naringenin. Code numbers for each open reading frame tested are shown beneath their respective bars, and pMP220 represents the empty vector negative control. The results are averages of three experiments.

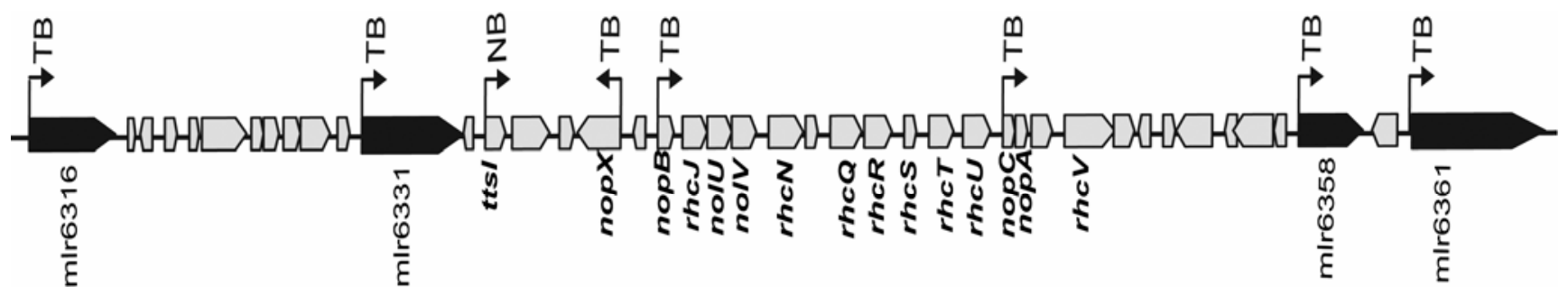

Fig. 3. Type III secretion system (T3SS) locus of MAFF303099. Predicted cis-elements are shown where; NB = nod box and TB = tts box. The four open reading frames corresponding to the genes identified in this study as belong to the T3SS regulon are shown in black. 
Mlr6358 and Mlr6361 are secreted by the T3SS.

Secretion was tested by creating translational fusions of a triple $(3 \times)$ copy of the FLAG peptide to N-terminal portions of Mll6337 (NopX) (150 aa), Mlr6358 (160 aa, using the start codon of the annotated ORF), Mlr6361 (59 aa), Mlr6316 (75 aa), Mlr6316 (160 aa), and Mlr6331 (177 aa). The 3× FLAG peptide was added to the final $\mathrm{C}$-terminal residue of each fragment. Constructs were conjugated into MAFF303099 and the rhcN mutant, that both constitutively express Rhizobium leguminosarum nodD. Strains containing the Mlr6316 and Mlr6331 fusion proteins were strongly affected for growth and, thus, it was not possible to study secretion.

The 3x FLAG fusions to NopX (Fig. 5A), Mlr6361 (Fig. 5B), and Mlr6358 (Fig. 5C) were detected in supernatants of MAFF303099 cultures grown in the presence of naringenin but not if naringenin was absent; nor were they secreted from the $r h c N$ mutant. In all cases, expression of the fusion proteins could also be seen intracellularly in the absence of naringenin, probably due to a low residual promoter activity, amplified because of the relatively high copy number of the pBB1-RMCS4 carrying the fusions.

\section{Nodulation phenotype of an mlr6361 mutant.}

A MAFF303099 mlr6361 mutant was created by the integration of a nonpolar gentamycin $(\mathrm{Gm})$-resistance cassette at nucleotide position 4,751 of the mlr6361 ORF. Although nonpolar, the cassette alters the translational phase downstream of its integration so that the C-terminal 1,470 aa of Mlr6361 (including the shikimate kinase-like domain) will not be synthesized. Nodulation experiments were carried out with Leucaena leucocephala but only small white nodules were observed (data not shown). Thus, it is not the shikimate kinase-like domain of the effector Mlr6361 that is responsible for the T3SSgenerated block of nodule functioning on L. leucocephala.

Competitive nodulation tests were carried out by coinoculating Lotus glaber with a mixture (1:1) of the mlr6361 mutant and MAFF303099. At $28 \mathrm{dpi}$, the percentage of nodules occupied only by MAFF303099 was $52.5 \pm 2.5 \%$ whereas those occupied only by the mlr6361 mutant was $36.5 \pm 3.5 \%$.

\section{Expression level of selected nodulation genes.}

In accordance with the nodule occupancy data for L. glaber, preliminary experiments showed that the $r h c N$ mutant was also less competitive than MAFF303099 for nodulation of $L$. japonicus (data not shown). We investigated whether this phenotypic difference was also reflected in differential transcription levels of $L$. japonicus genes. In a previous report, we described the identification of several $L$. japonicus genes whose expression levels were significantly increased in MAFF303099-inoculated roots compared with noninoculated controls (D'Antuono et al.

Table 2. Amino-terminal analysis of MAFF303099 Nops and candidate effectors $^{\mathrm{a}}$

\begin{tabular}{lccc}
\hline $\begin{array}{l}\text { Protein } \\
\text { codified by }\end{array}$ & $\begin{array}{c}\text { No Asp or Glu } \\
\text { in the first 12 } \\
\text { amino acids }\end{array}$ & $\begin{array}{c}\text { Ile, Leu, Val, or Pro in } \\
\text { the third or fourth } \\
\text { amino acids }\end{array}$ & $\begin{array}{c}\mathbf{2 1 0 \%} \text { de Ser } \\
\text { in the first 50 } \\
\text { amino acids }\end{array}$ \\
\hline nopX & + & + & $\mathbf{+ 2 2 \%}$ \\
nopB & + & + & $\mathbf{+ 1 4 \%}$ \\
nopA & + & - & $\mathbf{+ 1 0 \%}$ \\
nopC & + & - & $\mathbf{+ 1 0 \%}$ \\
mlr6361 & + & + & $\mathbf{+ 2 2 \%}$ \\
mlr6331 & + & - & $-7 \%$ \\
mlr6316 & - & - & $-2 \%$ \\
mlr6358 & - & - & $+18 \%$ \\
mlr6358 & + & + & $\mathbf{+ 2 4 \%}$ \\
\hline
\end{tabular}

${ }^{a}$ Data in bold indicate the protein has the specific $\mathrm{N}$-terminal characteristic.

${ }^{\mathrm{b}}$ Alternative open reading frame.
2008). Expression of two genes in particular, encoding flavanone 3-hydroxylase $(\mathrm{F} 3 \mathrm{H})$ and gibberellin-2 oxidase (GA-2 oxidase), was associated with an active nodule (D'Antuono et al. 2008; Kouchi et al. 2004). At 17 dpi, we analyzed the expression levels of these two genes in L. japonicus roots inoculated with MAFF303099 or the $r h c N$ mutant, comparing their levels with those of noninoculated roots. Relative expression levels of GA-2 OXIDASE and F3H (with respect to noninoculated roots) were significantly reduced in roots inoculated with $r h c N$ mutant compared with MAFF303099 (Fig. 6A).

The putative transcription factor $N I N$ is induced relatively early by the action of Nod factors (Imaizumi-Anraku et al. 2005) and its expression then continuously increases (albeit initially slowly) during the process of nodulation (D'Antuono et al. 2008; Radutoiu et al. 2003). Monitoring NIN expression levels during nodule formation could be a good marker for timing of nodulation processes and indicate any problems caused by the rhcN mutant. Expression levels of NIN were analyzed at earlier timepoints (7 and $12 \mathrm{dpi}$ ). NIN expression was induced in both MAFF303099- and $r h c N$-mutant-inoculated roots compared with noninoculated roots. NIN expression induced by MAFF303099 did not vary significantly between the two timepoints. The $r h c N$ mutant caused dramatic effects
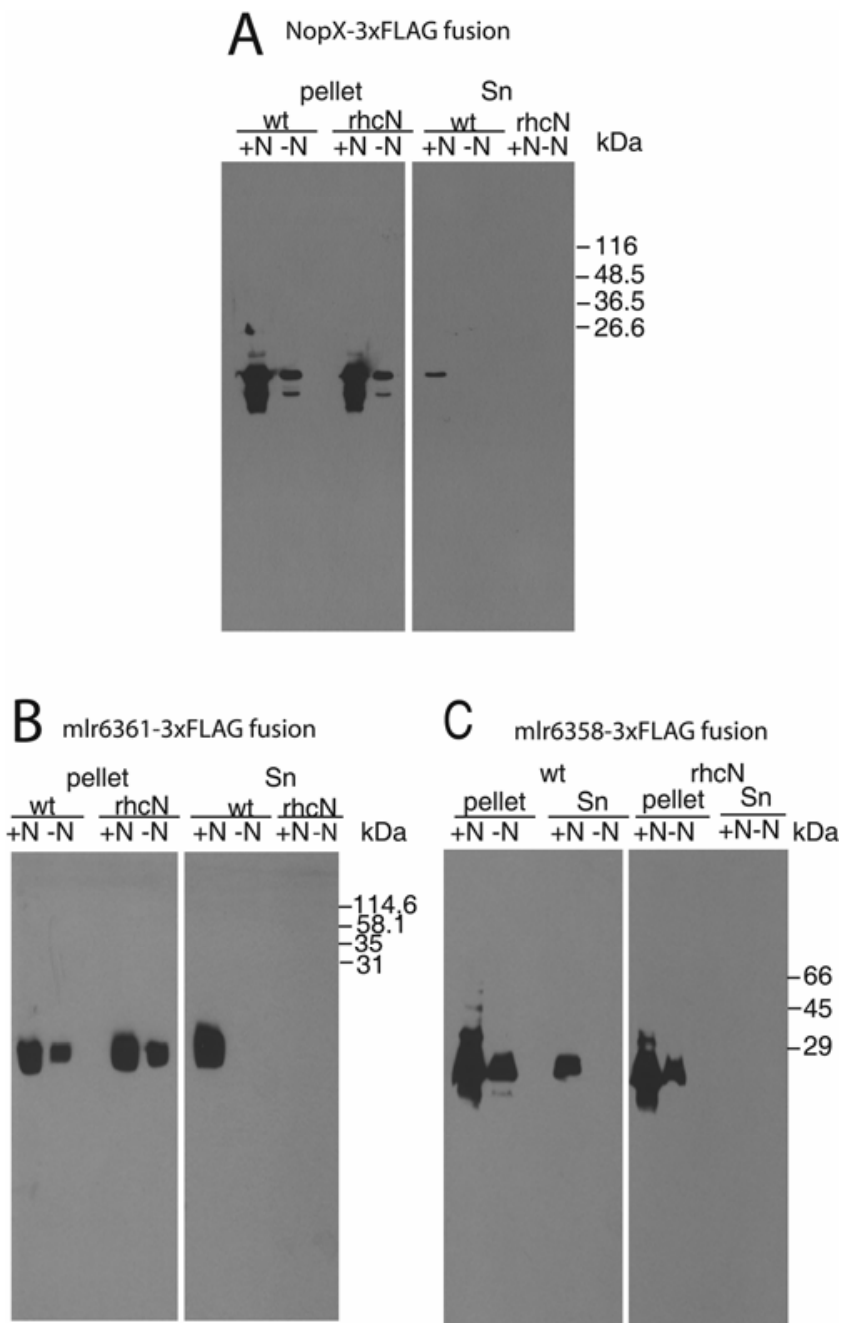

Fig. 5. Secretion of triple FLAG-amino terminal fusions of NopX, mlr6361, and mlr6358. Supernatant (Sn) and intracellular (labeled as "pellet") proteins were isolated from MAFF303099 and its $r h c N$ mutant grown with or without naringenin (shown by $+\mathrm{N}$ or $-\mathrm{N}$ ). Proteins were separated by $10 \%$ sodium dodecyl sulfate polyacrylamide gel electrophoresis and then immunoblotted, probing with an anti-FLAG antibody. Positions of size markers loaded onto the gels are labeled (in kilodaltons). 
on NIN expression, however. At $7 \mathrm{dpi}$, levels were double of those induced by MAFF303099; conversely, at 12 dpi, they showed a sixfold reduction in roots inoculated with the $r h c N$ mutant relative to those inoculated with MAFF303099 (Fig. $6 B)$.

\section{DISCUSSION}

In this work, we show that MAFF303099 has a functional T3SS which is regulated as in other rhizobia by a process that involves flavonoids and the transcription factors NodD and TtsI (Marie et al. 2004; Viprey et al. 1998). We used NodD of $R$. leguminosarum and naringenin to induce expression of MAFF303099 T3SS genes. Both $t t s I$ and nopX were induced by naringenin, with a delayed expression of nopX relative to $t t s I$, as expected if TtsI is necessary for expression of TB-controlled genes (such as nopX). Maximal expression was observed $24 \mathrm{~h}$ after induction as also described for B. japonicum USDA110 and NGR234 (Kobayashi et al 2004; Krause et al 2002; Marie et al. 2004). Having demonstrated T3SS gene inducibility, the same system was used to identify potential T3SS-secreted proteins. Western blotting with an anti-NopA antibody from NGR234 and mass spectrometry analyses identified the MAFF303099 NopA and NopX orthologs as being secreted by the T3SS.
Identification of Nops by differential detection (comparing proteins secreted by wt and the $r h c N$ mutant) in gels was difficult, however. Thus, to detect other proteins secreted by the T3SS, a new strategy was adopted to search for putative genes under the control of TtsI. In a method similar to that used in some plant pathogens (Vencato et al. 2006), we carried out an in silico analysis to identify $\mathrm{TB}$ in regions upstream of predicted ORF. Then, transcriptional lacZ fusions were constructed for some of these TB-containing promoter regions to confirm whether the promoter was induced by naringenin. Four new genes, mlr6316, mlr6361, mlr6331, and mlr6358, were identified as inducible by the NodD/flavonoid cascade in MAFF303099. All are within the symbiotic island and flank the T3SS cluster. In many other T3SS-possessing bacteria, ORF in these regions often encode effectors (Alfano et al 2000).

We also assayed three promoters predicted as containing TB upstream of genes outside the symbiotic island ( $\mathrm{mlr} 4967$, $m l r 5253$, and $m l r 7346$ ). Although expressed, they were not induced by naringenin. In NGR234, the promoter of $y 4 \mathrm{mF}$ was also predicted to contain a TB but, similarly, was not flavonoid regulated, despite being transcriptionally active (Wassem et al. 2008). Thus, the TtsI-controlled regulon of rhizobia may not be as big as predicted through in silico searches or, perhaps, additional signals (to flavonoids alone) are required for full activation of TB-controlled genes.

A
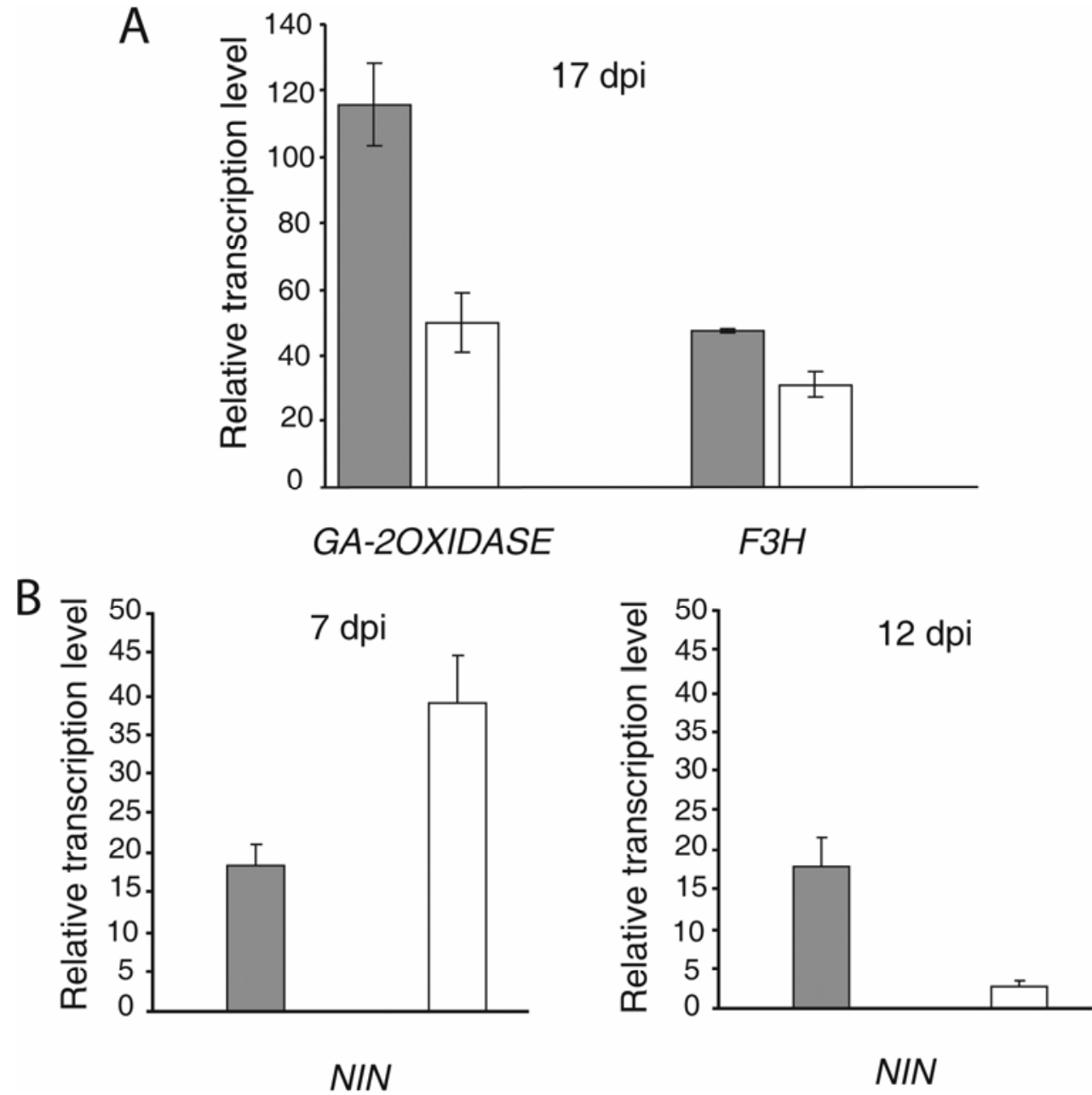

Fig. 6. Expression levels of Lotus japonicus genes after inoculation with MAFF303099 and the rhcN mutant. gibberellin-2oxidase (GA 2-OXIDASE) and flavanone 3-hydroxylase $(F 3 H)$ expression were determined $\mathbf{A}$, at 17 days postinoculation (dpi) whereas $\mathbf{B}, N I N$ expression was determined at 7 and 12 dpi. Expression levels after MAFF303099 inoculation are shown with gray bars and those from rhcN inoculation with white bars. Relative transcription level values indicate the fold increase in expression compared with that of noninoculated roots at the same time point. Four replicates, representing two biological replicates, were performed for each condition analyzed. The error bars indicate standard deviation. 
Interestingly, mlr6316 is a homolog of msi059 of R7A-a gene encoding a translocated effector from this strain (Hubber et al. 2004). In R7A, this gene is preceded by a T4SS vir box consensus sequence and is induced via the NodD/flavonoid cascade (Hubber et al. 2007). However, in MAFF303099, mlr6316 is preceded by a functional $t t s$ box. This could be an example of adaptive evolution, conserving in these two strains the same effector but under the control of different secretion systems. Furthermore, as a T4SS-secreted effector, Msi059 most likely has a signal for secretion in its C-terminal region (Vergunst et al. 2005), whereas the protein encoded by mlr6316, if secreted by the MAFF303099 T3SS, should have an N-terminal secretion signal. The characteristic N-terminal secretion pattern described for effectors of Pseudomonas spp. was not identified in the $m l r 6316$ gene product. Furthermore, it was not possible to show secretion of a $5^{\prime}$ portion of the mlr6316 gene fused to the $3 \times$ FLAG-encoding sequence, although this was due to the fact that the fusion interferes with bacterial growth.

Genes $m l r 6361$ and $m l r 6331$ have an ortholog in $P$. syringae (gene PSPPH1525) (Vencato et al. 2006). The protein encoded by PSPPH1525 was proposed to be secreted by the T3SS but this has not yet been demonstrated. This putative protein and its homologs in Ralstonia solanacearum and $X$. axonopotis all possess a conserved multidomain region (PRK01969) of unknown function (Vencato et al. 2006). As well as this multidomain, the predicted proteins encoded by mlr6361 and mlr6331 also contain an additional domain with homology to the enzyme shikimate kinase (see below). Furthermore, in a large yeast two-hybrid analysis, an interaction between the proteins encoded by mlr6361 and mlr6331 was also reported (Shimoda et al. 2008). Thus, in total, the protein encoded by mlr6361 presents an N-terminal sequence that direct its secretion, a PRK01969 domain, an unidentified domain that allows its interaction with another protein, and a shikimate kinase-like domain. Taken together with the presence of an upstream regulatory domain involved in its transcriptional activation, Mlr6361 has all the multifunctional characteristics of T3SS effectors (McCann and Guttman 2008).

Shikimate kinase is the fifth enzyme that participates in the shikimate pathway, found in bacteria, fungi, and plants. It is a seven-step biosynthetic pathway which converts erythrose-4phosphate to chorismic acid, an important intermediate for the synthesis of aromatic compounds such as aromatic amino acids, p-aminobenzoic acid, folate, and ubiquinone. Shikimate kinase catalyzes the phosphorylation of the 3-hydroxyl group of shikimic acid using ATP. In rice, shikimate kinase (EC 2.7.1.71) was shown to be involved in a plant defense response (Kasai et al. 2005). In bacteria, it has been implicated in cellular division (Vinella et al. 1996). Shikimate is a constituent of plant root exudates and could be used as a nutrient or chemoattractant by rhizosphere bacteria (Brencic and Winans 2005). MAFF303099 contains another gene potentially encoding a shikimate kinase on the chromosome ( $m l l 3573$, aroK). In $S$. meliloti, there are four genes that possess a domain with homology to shikimate kinase; expression of one of them (SMc99695, aroK) was induced by a specific flavonoid and by root exudates (Zhang and Cheng 2006).

In $P$. syringae, it was proposed that the signal to be secreted by T3SS resides in the amino acid sequence of the N-terminal region of the protein (Gosh 2004). The MAFF303099 orthologs of NopA and NopB, components of the T3SS pili in NGR234 (Saad et al. 2008); NopC, another nodulation outer protein (Deakin et al. 2005); and NopX, a component of the translocon (Marie et al. 2003) all have the pattern proposed for Pseudomonas effectors. In the four new NodD/flavonoid cascade-inducible genes identified in this work, only mlr6361 codes for a protein with the conserved secretion amino acid pattern proposed for $P$. syringae. Translational fusions to a $3 \times$ FLAG peptide demonstrated the naringenin- and T3SS-dependent secretion of MAFF303099 NopX and the proteins encoded by mlr6361 and mlr6358. Thus, the NH2-terminal regions of NopX, Mlr6361, and Mlr6358 contain signals to be secreted by the T3SS, despite the fact that Mlr6358 did not have the N-terminal features predicted to be characteristic of secreted proteins.

The overlapping regions of amino acid sequences of the proteins encoded by mlr6361, mlr6331, and mlr6358 might indicate that $m \operatorname{lr} 6361$ is the result of the shuffling process called terminal reassortment (Stravinides et al. 2006). Mlr6358 could constitute an orphaned effector terminus (McCann and Guttman 2008) that could be fused to another functional domain, giving it the capacity to be secreted by the T3SS (i.e., the creation of a new effector).

Coinoculation experiments revealed that a T3SS mutant displayed reduced competitiveness compared with the wt strain. The defect of the T3SS mutant strain in inducing a normal nodulation process on L. japonicus is also seen in the altered expression levels of three different genes known to be involved in nodulation. GA-2 OXIDASE and $F 3 H$ are strongly induced in mature nodules (Kouchi et al. 2004) and their lower expression at 17 dpi with the $r h c N$ mutant might have been caused by the presence of more immature nodules or a lower number of mature nodules compared with plants inoculated with the wt strain (at this timepoint). Mutation of $r h c N$ reduces NIN expression at 12 but not at $7 \mathrm{dpi}$. Thus, NIN expression levels seen with the rhcN mutant give an indication of the moment at which the nodulation process was negatively affected. NIN expression is induced by Nod factors (Imaizumi-Anraku et al. 2005) and then its expression is maintained and increased during nodulation (D'Antuono et al. 2008; Radutoiu et al. 2003). Although NIN function is still not totally understood, it was previously demonstrated that NIN expression is required for positive regulation of nodule organogenesis and bacterial entry (Geurts et al. 2005; Marsh et al. 2007). Further macroscopic and microscopic analyses of nodulation processes will be carried out to correlate the levels of NIN expression with formation of infection threads, nodule primordia, and active, mature nodules.

The potential importance of the Mlr6361 shikimate kinaselike activity in the nodulation process was shown by the inducible expression of mlr6361 by plant flavonoids in both $M$. loti and $S$. meliloti as well as its capacity to be secreted by the $M$. loti T3SS. Furthermore mutation of mlr6361 that prevents synthesis of the shikimate kinase domain resulted in a strain with an intermediate degree of competitiveness relative to the wt and T3SS mutant phenotypes. Thus, MAFF303099 most likely secretes other effectors that contribute to its competitiveness on L. glaber. This was confirmed by nodulation tests on Leucaena leucocephala, where the MAFF303099 T3SS was responsible for a block in correct nodule functioning, confirming results obtained by Hubber and associates (2004). The mlr6361 mutant also invoked only pseudonodules on L. leucocephala and, thus, it seems that there must be another effector secreted by the MAFF303099 T3SS. A strong candidate would be the protein encoded by mlr6316, whose homolog Msi059 in R7A is partly responsible for the ineffective nodulation on $L$. leucocephala by this strain (Hubber et al. 2004). It remains a goal of our work to identify those effectors that influence nodulation of MAFF303099 legume hosts and to investigate the responses of Lotus spp. to them.

\section{MATERIALS AND METHODS}

Bacterial strains and growth media.

Bacterial strains and plasmids used in this study are listed in Supplementary Table 1. Escherichia coli strains were grown at 
$37^{\circ} \mathrm{C}$ in Luria-Bertani media. MAFF303099 strains were grown at $28^{\circ} \mathrm{C}$ in $\mathrm{AB}$ minimal medium (Douglas et al. 1985) supplemented with sucrose $(0.5 \%$, wt/vol). When necessary, antibiotics were added to the following final concentrations $(\mu \mathrm{g} / \mathrm{ml}): \mathrm{Gm}$ at 30 , ampicillin (Amp) at 100 , neomycin $(\mathrm{Nm})$ at 100 , and tetracycline (Tc) at 10 for E. coli or 1 for M. loti. For T3SS induction, naringenin was added to cultures at an optical density at $600 \mathrm{~nm}\left(\mathrm{OD}_{600}\right)$ of 0.1 , to a final concentration of $1 \mu \mathrm{M}$.

\section{Creation of MAFF303099 rhcN and mlr6361 mutants.}

An internal fragment of the mlr6342 gene was amplified from MAFF303099 by polymerase chain reaction (PCR) with the primers 5'-AGTACGGCAAAGGGGAT-3' and 5' CGCCTTGCTTGTATTCTC-3' and ligated into pGEMTEasy. The resulting plasmid was named pGEMTEasy-rhcN. A Gm cassette, devoid of a transcriptional terminator sequence (Ugalde et al. 2000), was introduced into a unique EcoRI site. The gene fragment containing the Gm cassette was cut out of pGEMTEasy-rhcN::Gm with $S p h \mathrm{I}$ and ligated to the pK18mobTc. The resulting plasmid, pK18mobTc-rhcN::Gm, was used to transform $E$. coli $\mathrm{S} 17 \lambda$ pir strain and then was introduced into MAFF303099 pMP2112 by biparental conjugation. Gm-resistant clones were isolated and double recombination events were selected by testing sensitivity to $\mathrm{Nm}$ and Tc. On this basis, a mutant named MAFF303099 $r h c N$ was selected. PCR analysis showed that the mutant resulted from a double crossover event.

An internal fragment of the mlr6361 gene was amplified from MAFF303099 with primers 5'-ACAAACCCGCCCCCT GAC-3' and 5'-GCCTTGAGCACTTGATAAAT-3' and ligated into pGEMT-Easy to create pGEMT-Easy-mlr6361. As described above, a Gm cassette was introduced into a unique Bam $\mathrm{H} 1$ restriction site. The gene fragment containing the $\mathrm{Gm}$ cassette was cut out of pGEMT-Easy-mlr6361::Gm with PstI and $S p h \mathrm{I}$ and ligated into pK18mobTc. E. coli transformation, M. loti conjugation, isolation of double recombination events, and confirmation by PCR of the resulting strain was carried out as described for the $r h c N$ mutant.

\section{Construction of transcriptional lacZ fusions.}

Plasmids pMP-mlr6361, pMP-mlr6358, pMP-mlr6316, pMP-mlr6331, pMP-mlr4967, pMP-mlr5253, pMP-mlr7346, pMP-nopX, and pMP-ttsI were constructed by cloning the corresponding promoter regions into the self-mobilizable, broadhost-range vector plasmid pMP220. Promoter regions were amplified by PCR and all constructions were sequenced to eliminate any possible mutations generated during amplification. Transformation of MAFF303099 pMP2112 with these plasmids was carried out by triparental mating. $\beta$-Galactosidase activity was determined at different post-induction time according to established protocols (Sambrook et al. 1989).

\section{Construction of $3 \times$ FLAG translational fusions.}

pBAD-mlr6361, pBAD-mlr6316, pBAD-mlr6358, and pBAD-nop $X$ were constructed by cloning the respective sequences encoding the N-terminal portion of the protein, together with the upstream promoter region into the vector pBAD $3 \times$ FLAG. Each promoter and $\mathrm{N}$-terminal encoding sequences were amplified by PCR and sequenced to eliminate any possible alteration. The fragments containing the fusion to the $3 \times$ FLAG sequence were cut with restriction enzymes BamH1 and HindIII, then cloned into pBBR1MCS-4 in the opposite orientation to the lac promoter, to prevent nonspecific transcription. The resulting plasmids were transferred to MAFF303099 pMP2112 and to MAFF303099 rhcN pMP2112 by triparental mating.
Isolation of extracellular and intracellular proteins.

Supernatant proteins were prepared from MAFF303099 and derivatives by $\left(\mathrm{NH}_{4}\right)_{2} \mathrm{SO}_{4}$ precipitation as described by Marie and associates (2003) with slight modifications: bacterial-free culture medium was obtained by three consecutive centrifugations, one at 5,200 rpm and the other two at 7,300 rpm. Supernatant proteins were salted out with $\left(\mathrm{NH}_{4}\right)_{2} \mathrm{SO}_{4}$ at a final saturation of $80 \%$ and the pellet were dissolved in $50 \mathrm{mM}$ Tris$\mathrm{HCl}$ (pH 8.2), $3 \mathrm{mM} \beta$-mercaptoethanol, and phenylmethylsulfonyl fluoride, then dialyzed overnight against the same buffer. Samples were then precipitated with $10 \%$ trichloroacetic acid (TCA) and dissolved in cracking buffer. Modifications were necessary because a lot of polysaccharides coprecipitated if $\left(\mathrm{NH}_{4}\right)_{2} \mathrm{SO}_{4}$ was used alone, complicating subsequent handling of the proteins. Supernatant proteins for the analysis of $3 \times$ FLAG fused proteins were carried out by direct TCA precipitation as previously described (Krehenbrink and Downie 2008).

For total (intracellular) bacterial proteins, $1 \mathrm{ml}$ of the MAFF303099 cultures used above was centrifuged and the pellet dissolved in cracking buffer.

\section{Analysis of proteins}

by gel electrophoresis and mass spectrometry.

Proteins were separated by SDS polyacrylamide gel electrophoresis. Detection was made by silver nitrate or by Coomassie Brilliant Blue (Sigma-Aldrich, St. Louis) staining. For immunoblotting, anti-NopA of NGR234 (Marie et al. 2004) or commercially anti-FLAG M2 monoclonal antibody (Sigma) were used.

For protein identification by mass spectrometry, gels were stained by a silver-staining method using sodium thiosulfate (Gharahdaghi et al. 1999). The band of interest (NopX) was extracted and analyzed by matrix-assisted laser desorption ionization time-of-flight spectrometry (using the CEQUIBIEM service of the University of Buenos Aires, Argentina).

\section{Nodulation tests.}

For the competition assays, mutant and wt strains were mixed together and inoculated on Lotus glaber plants, as described previously (D'Antuono et al. 2005). At 4 weeks postinoculation, 10 nodules from each of three experiments were harvested, sterilized, and crushed separately in AB media. To determine the relative proportion of the mutant strain with respect to the wt strain in each nodule analyzed, serial dilutions were plated on $\mathrm{AB}(0.5 \%$ sucrose $)$ minimal medium with or without $\mathrm{Gm}$. The results are the average of the three experiments.

Leucaena leucocephala seed were surface sterilized and germinated on water for 3 days. Germinated plants were placed in vermiculite-filled Leonard jars and inoculated with bacterial suspensions in Fahareus media (Fahraeus 1957) at $\mathrm{OD}_{600}=$ 0.6 . The roots were observed 12 weeks postinoculation.

\section{Real-time PCR analysis.}

Surface-sterilized Lotus japonicus seed were germinated in water for 2 to 3 days. Germinated plants were placed in vermiculite-filled Leonard jars and inoculated with bacterial suspensions in Fahareus media at $\mathrm{OD}_{600}=0.6$. At 17 dpi, roots were cut and frozen in liquid nitrogen. RNA extractions were made using the RNeasy kit (Qiagen Sciences, Germantown, MD, U.S.A.) and quantitative reverse-transcription (qRT)-PCR analysis was made as previously described (D'Antuono et al. 2008).

\section{Bioinformatic analysis.}

The in silico searching for TB motifs as predicted by Krause and associates (2002) was made with the program CONSENSUS (van Helden et al. 2000). 


\section{ACKNOWLEDGMENTS}

The project was supported by grants from the Agencia Nacional de Promoción Científica y Tecnológica (PICT 2004 no. 20408) and from the Universidad Nacional de San Martín (28/E044). We acknowledge Ing. Agrónomo Joaquín Dante Pueyo from de E.E.A. of El Colorado, INTA, Formosa, Argentina, for the Leucaena leucocephala seed and the MAFF GENE BANK of the National Institute of Agrobiological Sciences (NIAS), 2-1-2, Kannondai, Tsukuba, Ibaraki, 305-8602, Japan, for the Mesorhizobium loti MAFF303099 strain. W. J. Deakin is supported by the Fonds National Suisse de la Recherche Scientifique (Projects 3100AO104097 and 3100A0-116858), the Département de 1'Instruction Publique du Canton de Genève, and the Université de Genève.

\section{LITERATURE CITED}

Alfano, J. R., and Collmer, A. 2004. Type III secretion system effector proteins: Double agents in bacterial disease and plant defense. Annu. Rev. Phytopathol. 42:385-414.

Alfano, J. R., Charkowski, A. O., Deng, W. L., Badel, J. L., PetnickiOcwieja, T., van Dijk, K., and Collmer, A. 2000. The Pseudomonas syringae Hrp pathogenicity island has a tripartite mosaic structure composed of a cluster of Type III secretion genes bounded by exchangeable effector and conserved effector loci that contribute to parasitic fitness and pathogenicity in plants. PNAS 97:4856-4861.

Bartsev, A. V., Deakin, W. J., Boukli, N. M., McAlvin, C. B., Stacey, G., Malnoë, P., Broughton, W. J., and Staehelin, C., 2004. NopL, an effector protein of Rhizobium sp. NGR234, thwarts activation of plant defense reactions. Plant Physiol. 134:871-879.

Batut, J., Andersson, S. G. E., and O'Callaghan, D. 2004. The evolution of chronic infection strategies in the $\alpha$-proteobacteria. Nat. Rev. 2:933945.

Brencic, A., and Winans, S. C. 2005. Detection of and response to signals involved in host-microbe interactions by plant-associated bacteria. Microbiol. Mol. Biol. Rev. 69:155-194.

Büttner, D., and Bonas, U. 2002. Getting across-bacterial type III effector proteins on their way to the plant cell. EMBO (Eur. Mol. Biol. Organ.) J. 21:5313-5322.

Chisholm S. T., Coaker, G., Day, B., and Staskawicz, B. J. 2006. Hostmicrobe interaction: Shaping the evolution of the plant immune response. Cell 1224:803-814.

Dai, W.-J., Zeng, Y., Xie, Z.-P., and Staehelin, C. 2008. Symbiosis-promoting and deleterious effects of NopT, a novel type 3 effector of Rhizobium sp. strain NGR234. J. Bacteriol. 190:5101-5110.

Dangl, J. L., and Jones, J. D. 2001. Plant pathogens and integrated defence responses to infection. Nature 411:826-833.

D'Antuono, A. L., Casabuono, A., Couto, A., Ugalde, R. A., and Lepek, V. C. 2005. Nodule development induced by Mesorhizobium loti mutant strains affected in polysaccharide synthesis. Mol. Plant-Microbe Interact. 18:446-457.

D’Antuono, A. L., Ott, T., Krusell, L., Voroshilova, V., Ugalde, R. A., Udvardi, M., and Lepek, V. C. 2008. Defects in rhizobial cyclic glucan and lipopolysaccharide synthesis alter legume gene expression during nodule development. Mol. Plant-Microbe Interact. 21:50-60.

Deakin, W. J., Marie, C., Saad, M. M., Krishnan, H. B., and Broughton, W. J. 2005. NopA is associated with cell surface appendages produced by the type III secretion system of Rhizobium sp. strain NGR234. Mol. Plant-Microbe Interact. 18:499-507.

de Lyra, M. C. C. P., López-Baena, F. J., Madinabeitia, N., Vinardell, J. M., Espuny, M. R., Cubo, M. T., Bellogín, R. A., Ruiz-Sainz, J. E., and Ollero, F. J. 2006. Inactivation of the Sinorhizobium fredii $\mathrm{HH} 103$ rhcJ gene abolishes nodulation outer proteins (Nops) secretion and decreases the symbiotic capacity with soybean. Int. Microbiol. 9:125-133.

Desveaux, D., Singer, A. U., Wu, A., McNulty, C., Musselwhite, L., Nimchuk, Z., Sondek, J., and Dangl, J. L. 2007. Type III effector activation via nucleotide binding, phosphorylation, and host target interaction. PLOS Pathogens 3:456-469.

D'Haeze, W., Glushka, J., De Rycke, R., Holsters, M., and Carlson, R. W. 2004. Structural characterization of extracellular polysaccharides of Azorhizobium caulinodans and importance for nodule initiation on Sesbania rostrata. Mol. Microbiol. 52:485-500.

Douglas, C. J., Staneloni, R. J., Rubin, R. A., and Nester, E. W. 1985. Identification and genetic analysis of an Agrobacterium tumefaciens chromosomal virulence region. J. Bacteriol. 161:850-860.

Fåhraeus, G., 1957. The infection of clover root hair by nodule bacteria studied by a single slide technique. J. Gen. Microbiol. 16:374-381.

Gage, D. J. 2004. Infection and invasion of roots by symbiotic, nitrogen fixing rhizobia during nodulation of temperate legumes. Microbiol. Mol. Biol. Rev. 68:280-300.
Geurts, R., Fedorova, E., and Bisseling, T. 2005. Nod factor signaling genes and their function in the early stages of Rhizobium infection. Curr. Opin. Plant Biol. 8:346-352.

Gharahdaghi F., Weinberg, C. R., Meagher, D. A., Imai, B. S., and Mische, S. M. 1999. Mass spectrometric identification of proteins from silverstained polyacrylamide gel: A method for the removal of silver ions to enhance sensitivity. Electrophoresis 20:601-605.

Gosh, P. 2004. Process of protein transport by the type III secretion system. Microbiol. Mol. Biol. Rev. 68:771-795.

Harrison, J., Jamet, A., Muglia, C. I., Van de Sype, G., Aguilar, O. M., Puppo, A., and Frendo, P. 2005. Glutathione plays a fundamental role in growth and symbiotic capacity of Sinorhizobium meliloti. J. Bacteriol. 187:168-174.

Hubber, A., Vergunst, A. C., Sullivan, J. T., Hooykaas, P. J. J., and Ronson, C. W. 2004. Symbiotic phenotypes and translocated effector proteins of the Mesorhizobium loti strain R7A VirB/D4 type IV secretion system. Mol. Microbiol. 54:561-574.

Hubber, A. M., Sullivan, J. T., and Ronson, C. W. 2007. Symbiosis-induced cascade regulation of the Mesorhizobium loti R7A VirB/D4 type IV secretion system. Mol. Plant-Microbe Interact. 20:255-261.

Imaizumi-anraku, H., Takeda, N., Charpentier, M., Perry, J., Miwa, H., Umehara, Y., Kouchi, H., Murakami, Y., Mulder, L., Vickers, K., Pike, J., Downie, J. A., Wang, T., Sato, S., Asamizu, E., Tabata, S., Yoshikawa M., Murooke, Y., Wu, G., Kawaguchi, M., Kawasaki, S., Parniske, M., and, Hayashi, M. 2005. Plastid proteins crucial for symbiotic fungal and bacterial entry into plant roots. Nature 433:527-531.

Jamet, A., Sigaud, S., Van de Sype, G. Puppo, A., and Hérouart, D. 2003. Expression of the bacterial catalase genes during Sinorhizobium meliloti-Medicago sativa symbiosis and their crucial role during the infection process. Mol. Plant-Microbe Interact. 16:217-225.

Kambara, K., Ardissone, S., Kobayashi, H., Saad, M. M., Schumpp, O., Broughton, W. J., and Deakin, W. J. 2009. Rhizobia utilize pathogenlike effector proteins during symbiosis. Mol. Microbiol. 71:92-106.

Kaneko, T., Nakamura, Y., Sato, S., Asamizu, E., Kato, T., Sasamoto, S., Watanabe, A., Idesawa, K., Ishikawa, A., Kawashima, K., Kimura, T. Kishida, Y., Kiyokawa, C., Kohara, M., Matsumoto, M., Matsuno, A., Mochizuki, Y., Nakayama, S., Nakazaki, N., Shimpo, S., Sugimoto, M., Takeuchi, C., Yamada, M., and Tabata, S. 2000a. Complete genome structure of the nitrogen-fixing bacterium Mesorhizobium loti. DNA Res. 7:331-338.

Kaneko, T., Nakamura, Y., Sato, S., Asamizu, E., Kato, T., Sasamoto, S., Watanabe, A., Idesawa, K., Ishikawa, A., Kawashima, K., Kimura, T., Kishida, Y., Kiyokawa, C., Kohara, M., Matsumoto, M., Matsuno, A., Mochizuki, Y., Nakayama, S., Nakazaki, N., Shimpo, S., Sugimoto, M., Takeuchi, C., Yamada, M., and Tabata, S. 2000b. Complete genome structure of the nitrogen-fixing bacterium Mesorhizobium loti. DNA Res. (Suppl.) 7:381-406.

Kasai, K., Kanno, T., Akita, M., Ikejiri-Kanno, Y., Wakasa, K., and Tozawa, Y. 2005. Identification of three shikimate kinase genes in rice: Characterization of their differential expression during panicle development and of the enzymatic activities of the encoded proteins. Planta 222:438447.

Kobayashi, H., Naciru-Graven, Y., Broughton, W. J., and Perret, X. 2004. Flavonoids induce temporal shifts in gene-expression of nod-box controlled loci in Rhizobium sp. NGR234. Mol. Microbiol. 51:335-347.

Kouchi, H., Shimomura, K., Hata, S., Hirota, A., Wu, G., Kumagai, H., Tajima, S., Suganuma, N., Suzuki, A., Aoki, T., Hayashi, Yakoyama, T., Ohyama, T., Asamizu, E., Duwata, C., Shibata, D., and Tabata, S. 2004. Large-scale analysis of gene expression profiles during early stages of root nodule formation in a model legume, Lotus japonicus. DNA Res. $11: 263-274$.

Krause, A., Doerfel, A., and Göttfert, M. 2002. Mutational and transcriptional analysis of the type III secretion system of Bradyrhizobium japonicum. Mol. Plant-Microbe Interact. 15:1228-1235.

Krehenbrink, M., and Downie, J. A. 2008. Identification of protein secretion systems and novel secreted proteins in Rhizobium leguminosarum bv. viciae. BMC Genomics 9:55.

Lohar, D. P., Sharapova, N., Endre, G., Peñuela, S., Samac, D., Town, C., Silverstein, K. A. T., and VandenBosch, K. A. 2006. Transcript analysis of early nodulation events in Medicago truncatula. Plant Physiol. 140:221-234.

López-Lara, I. M., van den Berg, J. D. J., Thomas-Oates, J. E., Glushka, J., Lugtenberg, B. J. J., and Spaink, H. P. 1995. Structural identification of the lipo-chitin oligosaccharide nodulation signals of Rhizobium loti. Mol. Microbiol. 15:627-638.

Lorio, J. C., Kim, W. W., and Krishnan, H. B. 2004. NopB, a soybean cultivar-specificity protein from Sinorhizobium fredii USDA257, is a type III secreted protein. Mol. Plant-Microbe Interact. 17:1259-1268.

Ma, W., Guinel, F. C., and Glick, B. R. 2003. Rhizobium leguminosarum biovar viciae 1-aminocyclopropane-1-carboxylate deaminase promotes 
nodulation of pea plants. Appl. Environ. Microbiol. 69:4396-4402.

Marie, C., Deakin, W. J., Viprey, V., Kopciñska, J., Golinowski, W. Krishnan, H. B., Perret, X., and Broughton, W. J. 2003. Characterization of Nops, nodulation outer proteins, secreted via the type III secretion system of NGR234. Mol. Plant-Microbe Interact. 16:743-751.

Marie, C., Deakin, W. J., Ojanen-Reuhs, T., Diallo, E., Reuhs, B., Broughton, W. J., and Perret, X. 2004. TtsI, a key regulator of Rhizobium species NGR234 is required for type III-dependent protein secretion and synthesis of rhamnose-rich polysaccharides. Mol. Plant-Microbe Interact. 17:958-966.

Marsh, J. F., Rakocevic, A., Mitra, R. M., Brocard, L., Sun, J., Eschstruth, A., Long, S. R., Schultze, M., Ratet, P., and Oldroyd, F. E. D. 2007. Medicago truncatula NIN is essential for rhizobial-independent nodule organogenesis induced by autoactive calcium/calmodulin-dependent protein kinase. Plant Physiol. 144:324-335.

McCann, H. C., and Guttman, D. S. 2008. Evolution of the type III secretion system and its effectors in plant-microbe interactions. New Phytol. 177:33-47.

Niehaus, K., Kapp, D., and Pühler, A. 1993. Plant defence and delayed infection in alfalfa pseudonodules induced by an exopolysaccharide (EPS I)-deficient Rhizobium meliloti mutant. Planta 190:415-425.

Radutoiu, S., Madsen, L H., Madsen, E. B., Felle, H. H., Umehara, Y., Grønlund, M., Sato, S., Nakamura, Y.,Tabata, S., Sandal, N., and Stougaard, J. 2003. Plant recognition of symbiotic bacteria requires two LysM receptor-like kinases. Nature 425:585-591.

Rodrigues, J. A., López-Baena, F. J., Ollero, F. J., Vinardell, J. M., Espuny, M. R., Bellogín, R. A., Ruiz-Sainz, J. E., Thomas, J. R., Sumpton, D., Aula, J., and Thomas-Oates, J. 2007. NopM and NopD are rhizobial nodulation outer proteins: Identification using LC-MALDI and LC-ESI with a monolithic capillary column. J. Proteome Res. 6:1029-1037.

Saad, M. M., Staehelin, C., Broughton, W. J., and Deakin, W. J. 2008. Protein-protein interactions within type III secretion system-dependent pili of Rhizobium sp. strain NGR234. J. Bacteriol. 190:750-754.

Sambrook, J., Fritsch, E. F., and Maniatis, T. 1989. Molecular Cloning: A Laboratory Manual. Cold Spring Harbor Laboratory Press, Cold Spring Harbor, NY, U. S.A.

Schechter, L. M., Vencato, M., Jordan, K. L., Schneider, S. E., Schneider, D. J., and Collmer, A. 2004. Multiple approaches to a complete inventory of Pseudomonas syringae pv. tomato DC3000 type III secretion system effector proteins. Mol. Plant-Microbe Interact. 19:1180-1192.

Shimoda, Y., Mitsui, H., Kamimatsuse, H., Minamisawa, K., Nishiyama, E., Ohtsubo, Y., Nagata, Y., Tsuda, M., Shinpo, S., Watanabe, A., Kohara, M., Yamada, M., Nakamura, Y., Tabata, S., and Sato, S. 2008 Construction of signature-tagged mutant library in Mesorhizobium loti as a powerful tool for functional genomics. DNA Res. 15:297-308.

Skorpil P., Saad, M. M., Boukli, N. M., Kobayashi, H., Ares-Orpel, F., Broughton, W. J., and Deakin, W. J. 2005. NopP, a phosphorylated effector of Rhizobium sp. strain NGR234, is a major determinant of nodulation of the tropical legumes Flemingia congesta and Tephrosia vogelii. Mol. Microbiol. 57:1304-1317.

Soto, M. J., Sanjuán, J., and Olivares, J. 2006. Rhizobia and plant-pathogenic bacteria: Common infection weapons. Microbiology 152:3167-3174.
Stravrinides, J., Ma, W., and Guttman, D. S. 2006. Terminal reassortment drives the quantum evolution of type III effectors in bacterial pathogens. PLOS pathogens 2:913-921.

Sullivan, J. T., Trzebiatowski, J. R., Cruickshank, R. W., Gouzy, J., Brown, S. D., Elliot, R. M., Fleetwood, D. J., McCallum N. G., Rossbach, U., Stuart, G. S., Weaver, J. E., Webby, R. J., De Bruijn, F. J., and Ronson, C. W. 2002. Comparative sequence analysis of the symbiosis island of Mesorhizobium loti strain R7A. J. Bacteriol. 184:3086-3095.

Süss, C., Hempel, J., Zehner, S., Krause, A., Patschkowski, T., and Gottfert, M. 2006. Identification of genistein-inducible and type IIIsecreted proteins of Bradyrhizobium japonicum. J. Biotechnol. 126:6977.

Tellstrom, V., Usadel, B., Thimm, O., Stitt, M., Kuster, H., and Niehaus, K. 2007. The lipopolysaccharide of Sinorhizobium meliloti suppresses defense-associated gene expression in cell cultures of the host plant Medicago truncatula. Plant Physiol. 143:825-837.

Ugalde, J E., Czibener, C., Feldman, M. F., and Ugalde, R. A. 2000. Identification and characterization of the Brucella abortus phosphoglucomutase gene: Role of lipopolysaccharide in virulence and intracellular multiplication. Infect. Immun. 68:5716-5723.

Vasse, J., de Billy, F., and Truchet, G. 1993. Abortion of infection during the Rhizobium meliloti-alfalfa symbiotic interaction is accompanied by a hypersensitive reaction. Plant J. 4:555-566.

Vencato, M., Tian, F., Alfano, J. R., Buell, C. R., Cartinhour, S., DeClerck, G. A., Guttman, D. S., Stavrinides, J., Joardar, V., Lindeberg, M., Bronstein, P. A., Mansfield, J. W., Myers, C. R., Collmer, A., and Schneider, D. J. 2006. Bioinformatics-enabled identification of the HrpL regulon and type III secretion system effector proteins of Pseudomonas syringae pv. phaseolicola 1448A. Mol. Plant-Microbe Interact. 19:1193-1206.

Vergunst, A. C., van Lier, M. C., den Dulk-Ras, A., Stuve, T. A., Ouwehand, A., and Hooykaas, P. J. J. 2005. Positive charge is an important feature of the C-terminal transport signal of the VirB/D4-translocated proteins of Agrobacterium. PNAS U.S.A. 102:832-837.

Vinella, D., Gagny, B., Joseleau-Petit, D., D’Ari, R., Cashel, M. 1996 Mecillinam resistance in Escherichia coli is conferred by loss of a second activity of the AroK protein. J. Bacteriol. 178:3818-3828.

Viprey, V., Del Greco, A., Golinowski, W., Broughton, W. J., and Perret, X 1998. Symbiotic implications of type III protein secretion machinery in Rhizobium. Mol. Microbiol. 28:1381-1389.

Wassem, R., Kobayashi, H., Kambara, K., Le Quéré, A., Walker, G. C., Broughton, W. J., and Deakin, W. J. 2008. TtsI regulates symbiotic genes in Rhizobium species NGR234 by binding to tts boxes. Mol. Microbiol. 68:736-748.

Wei, M., Yokoyama, T., Minamisawa, K., Mitsui, H., Itakura, M., Kaneko, T., Tabata, S., Saeki, K., Omori, H., Tajima, S., Uchiumi, T., Abe, M., and Ohwada, T. 2008. Soybean seed extracts preferentially express genomic loci of Bradyrhizobium japonicum in the initial interaction with soybean, Glycine $\max (\mathrm{L}$.) Merr. DNA Res. 15:210-214.

Zhang, X., and Cheng, H. 2006. Identification of Sinorhizobium meliloti early symbiotic genes by use of a positive functional screen. Appl Environ. Microbiol. 72:2738-2748. 